Article

\title{
L1 Transfer in L2 Acquisition of English Verbal Morphology by Japanese Young Instructed Learners
}

\author{
Akiko Muroya \\ Faculty of Commerce, Nagoya University of Commerce and Business, Nisshin, Aichi Prefecture 470-0193, Japan; \\ amuroya@nucba.ac.jp
}

Received: 16 August 2018; Accepted: 13 December 2018; Published: 20 December 2018

check for updates

\begin{abstract}
Inflectional morphology has been considered as a particularly difficult area in second language (L2) acquisition (Lardiere 2008; Slabakova 2008). This paper reports on an empirical study investigating the L2 acquisition of English verbal morphology by Japanese young instructed learners. The aim of this study is to explore how the first language (L1) plays a role in the L2 acquisition of inflectional morphology, by applying the Feature Reassembly Hypothesis (FRH, Lardiere 2008, 2009) to a Japanese-English pairing. An elicited production task was administered to Japanese junior high school aged $12-15(n=102)$ and university students aged 19-20 $(n=30)$. The results show a difference with respect to accuracy rates and error types from previous L2 English studies, in terms of tense-aspect morphology. The findings provide evidence for the FRH's prediction that attributes morphological variability to L1-L2 contrasts in reassembly of feature matrices for morpholexical items.
\end{abstract}

Keywords: variability; tense-aspect morphology; feature reassembly; -tei-ru

\section{Introduction}

Inflectional morphology, termed the "bottleneck" (Slabakova 2008) of L2 development, or "the problem of L2 users" (Dekeyser 2005), has been regarded as the locus of difficulty in L2 acquisition. L2 learners exhibit variability (i.e., misuse, overuse, omission) in their use of functional morpholexical items (e.g., copulas, auxiliaries, markers for tense, aspect, agreement, determiners). There has been thus much generative L2 research into what could cause morphological variability. Recent research in L2 acquisition has explained possible sources of the persistent divergence through the role of formal features (phonological, syntactic, and semantic) (Slabakova 2016, p. 197). There are two different approaches to explain how L1 plays a role in the variability, both of which are subsumed under the Distributed Morphology (DM) framework (Halle and Marantz 1993) ${ }^{1}$; (Ionin 2013, p. 508). The Interpretability Hypothesis ${ }^{2}$ (Hawkins and Hattori 2006; Tsimpli and Mastropavlou 2008) proposes impaired syntactic representation due to L2 learners' inability to acquire the uninterpretable features in the L2 that are absent in their L1. The Feature Reassembly Hypothesis (Lardiere 2008, 2009), on the other hand, argues imperfect processing due to the L2 learners' failure to acquire the different configuration of the feature shared by both L1 and L2.

In some recent L2 studies examining different L1-L2 pairings and grammatical properties (Ionin and Montrul 2010; Hopp 2010; Yuan 2010), advanced adult L2 learners were able to overcome L1

1 Under the DM, it is assumed that lexical items are inserted into a syntactic node, where features on the lexical item have to form a subset of the features on the syntactic node.

2 The results of this study do not provide evidence for or against the $\mathrm{IH}$, as the main goal of the study was to examine the predictive power of the FRH. However, further research aims to compare the two approaches. 
transfer, while in others L2 processing was impeded. This is compatible with the FRH, which proposes that L2 processing depends on L1-L2 pairings, although any L1-L2 contrasts are ultimately acquirable. This study contributes to the current line of L2 generative research, by investigating the acquisition of different properties by beginner-intermediate young instructed learners in a different L1-L2 pairing.

This study aims to address a question of how L1-L2 contrasts in feature assembly affect the L2 acquisition process of verbal morphology, by applying the FRH's key assumptions to a Japanese-English pairing. The FRH assumes two continuous learning processes (feature selection and feature assembly) and three determinants of learnability (the same feature, the different configurations, and morpholexical correspondence). For tense, Japanese has a verbal suffix $-t a$ to encode [+past] (e.g., tazune-ta), which is morphosyntactically equivalent to English $-e d$ (e.g., ask-ed). Japanese has a suffix $-(r) u$ to denote [-past] (e.g., tazune $-r u)$ with any person [1st/2nd/3rd person] and number [+/-singular] features which Chomsky refers to as phi-feature. ${ }^{3}$ English, on the other hand, has the two forms: one is $\varnothing$ (zero suffix) to denote [-past] with [1st/2nd person] and [+/-singular] (e.g., I/we ask, you/you ask); the other is $-s$ to encode a specific bundle of three features [-past] with [3rd person] and [+singular] for subject-verb agreement (e.g., Jane/the girl/she ask-s). Turning to aspect, Japanese imperfective aspect form $-t e i-r u$ is associated with three aspectual features ([+progressive], [+habitual], and [+resultative]), while English be + -ing encodes only a [+progressive] feature. Considering the three determinants of learnability, it is predicted that while L1 Japanese learners are more likely to reassemble [+past] into the L2 item $-e d$, they will have more difficulty realising the three specified features on a single new lexical item $-s$ and reconfiguring only one feature [+progressive] into a pair of L2 items be + -ing.

A picture stimulus task was used to elicit both written and spoken data from L1 Japanese learners (aged 12-20) at beginner $(n=42)$, post-beginner $(n=60)$, and intermediate $(n=30)$ levels of English. Previous L2 English research produced results which shared the same accuracy order: copula be $>$ auxiliary be > irregular past forms $>$ regular past $-e d>3 S G-s$ (Goad et al. 2003; Ionin and Wexler 2002). This is consistent with the results in many L2 studies: suppletive inflection (copula be, auxiliary $b e$ ) is acquired faster/more accurately than affixal inflection (3SG $-s$, regular past -ed) (White 2008). However, the current study found a different accuracy order, with regular past tense $-e d$ and auxiliary $b e$ reversed: copula $b e>$ regular past $-e d>$ irregular past forms $>$ auxiliary be $>3 S G-s$. Furthermore, the two verbal morphemes exhibited another difference in the type of errors from other L2 English studies (Hawkins and Casillas 2008; Ionin and Wexler 2002; Haznedar 2001; White 2003a): (1) overuse of $-e d$ (e.g., drinked) in irregular past form contexts; (2) misuse of bare verbs and $-s$ in obligatory auxiliary be contexts, where imperfective aspect $(b e+-i n g)$, not present tense $(-s)$, must have been chosen to express an ongoing event (e.g., He study Japanese now./She eats breakfast now). The results confirm the FRH's prediction that attributes variability in inflectional morphology to L1-L2 contrasts in feature assembly. This suggests that the differences in accuracy rates and error types could be related to the three determinants of learnability.

The paper is organised as follows: Section 2 outlines tense and aspect (grammatical/lexical) in Japanese and English verbal morphology. Section 3 reviews the underlying assumptions of the Feature Reassembly Hypothesis (Lardiere 2008, 2009) and presents the application to Japanese and English verbal morphology. Section 4 presents previous L2 studies. Section 5 lays out the research questions and methodology. The results are summarised in Section 6, followed by discussion, some concluding remarks, and directions of future research in Section 7.

\section{Tense-Aspect Morphology in English and Japanese}

Both tense and grammatical aspect are classified as morphosemantic features. Comrie (1976, p. 1-3) explains the distinctions between tense and aspect: “Tense relates the time of the situation referred to 
some other time, usually to the moment of speaking", while "aspects are different ways of viewing the internal temporal constituency of a situation". Tense locates a situation on the timeline in relation to the moment of speech: non-past or past. By contrast, grammatical aspect expresses one's viewpoint of a situation: whether a situation is viewed as completed (perfective) or as ongoing (imperfective). In other words, perfective aspect views a situation as a bounded whole, while imperfective aspect views a situation as an internal temporal structure (Comrie 1976; Smith 1991, 1997). The situation refers to events, processes, and states. In addition, there is another aspect encoded in the inherent properties of lexical verbs, which is called lexical (inherent) aspect. Following Vendler (1967's four categories, lexical aspect consists of four aspectual classes of verbal predicates, defined by different combinations of three key semantic features' oppositions: (1) stative vs. dynamic; (2) durative vs. punctual; (3) telic vs. atelic, as illustrated in Table 1.

Table 1. Four lexical aspect classes of verbs.

\begin{tabular}{lcccc}
\hline Lexical Aspect Classes & Stative & Activities & Accomplishments & Achievements \\
\hline Aspectual Features & $k n o w$ & swim & swim one kilo metre & recognise \\
\hline [stative] & $\boldsymbol{V}$ & $\boldsymbol{V}$ & $\boldsymbol{V}$ \\
$\begin{array}{l}\text { [dynamic] } \\
\text { [durative] }\end{array}$ & $\boldsymbol{V}$ & $\boldsymbol{V}$ & $\boldsymbol{V}$ \\
$\left.\begin{array}{l}\text { [punctual] } \\
\text { [atelic] }\end{array}\right]$ telic] & $\boldsymbol{V}$ & $\boldsymbol{V}$ & $\boldsymbol{V}$ \\
\hline
\end{tabular}

The Aspect Hypothesis (Andersen and Shirai 1994; Robinson 1995) proposes that the acquisition of tense-aspect morphology is correlated with the four inherent lexical aspect classes. This suggests that the interpretation of grammatical markers depends on the lexical aspects of the verbal predicate which it is attached to.

Both English and Japanese encode tense and grammatical aspect via inflectional morphology, as shown in Table 2. However, imperfective markers differ as to the realisation of tense and aspect between English and Japanese. In English be $+-i n g$, auxiliary be denotes tense, while Japanese $-t e i-r u / t e i-t a$ changes its form for tense.

Table 2. Tense-aspect morphology in English and Japanese.

\begin{tabular}{llll}
\hline \multirow{2}{*}{ Tense } & & English & Japanese \\
\hline \multirow{2}{*}{ Grammatical Aspect } & Non-past & $-\varnothing /-s$ & $-(r) u$ \\
\cline { 2 - 4 } & Past & $-e d$ & $-t a$ \\
\cline { 2 - 4 } & Perfective & have $+-e n$ & $-t e i-r u / t a$ \\
\hline
\end{tabular}

In addition, in both English and Japanese, temporal and aspectual notions are denoted via adverbs/adverbial phrases. In English, the use of adverbs (e.g., yesterday, already) corresponds to the inflectional morphology (e.g., past, perfective), as given in Examples (1. a/b).

1. a. I watched that match yesterday.

b. I have already watched that match

On the other hand, in Japanese, it should be noted that adverbs such as 'kinou' (yesterday)' and ' $m o u^{\prime}$ (already) provide a morpheme - $t a$ with the respective interpretations, as shown in Examples (2. $a / b)$. 

a. Boku-wa kinoo
ano siai-o
mi-ta. (past tense)
I-TOP
yesterday
that match-ACC
watch-PAST
'I watched that match yesterday.'
b. Boku-wa moo
ano siai-o
mi-ta. (perfective aspect)
I-TOP already
that match-ACC
watch-PERFECTIVE
'I have already watched that match.'

\subsection{Simple Past Tense Marker: English - ed and Japanese - ta}

With regards to a past tense marker, English $-e d(3 . a, c, e, g)$ and Japanese $-t a(3 . b, \mathrm{~d}, \mathrm{f}, \mathrm{h})$ share the equivalent interpretation [+past], regardless of the four aspectual classes, as shown below.

3. a. Yutaro walked in the park.

[Activity]

b. Yutaro-ga kooen-de Yutaro-NOM park-LOC

arui-ta.

'Yutaro walked in the park.'

c. Yutaro painted a picture.

[Accomplishments]

d. Yutaro-ga e-o
Yutaro-NOM pict

kai-ta.

Yutaro-NOM picture-ACC paint-PAST

'Yutaro painted a picture.'

e. Yutaro arrived at the airport.

f. Yutaro-ga kuukoo-ni tui-ta. Yutaro-NOM airport-LOC arrive-PAST

[Achievement]

'Yutaro arrived at the airport.'

g. Yutaro wanted a bike.
h. Yutaro-wa jitensya-ga hosikat-ta. Yutaro-TOP bike-ACC want-PAST
'Yutaro wanted a bike.'

In Japanese, however, the past tense marker $-t a$ is often recognised as a "perfect marker or perfective aspect marker"4 (Diaz et al. 2008) when attached to a telic verb phrase (Ogihara 1999) or other telicity-marking components ${ }^{5}$ that are listed below.

- $\quad$ adverbs (e.g., moo 'already')

- adverbial phrases

(1) frame (e.g., 30-pun de 'in 30 minutes')

(2) durative (e.g., 30-pun kan 'for 30 minutes')

- $\quad$ overt numerals (e.g., $10-$ satu)

4 "a marker of perfect aspect" (Gabriele and Hughes 2015, p. 275); 'perfect' can be analysed as a tense (Kibort and Corbett 2010). Gabriele and Gabriele and Hughes (2015) refers to debate over whether the morpheme - ta is a past tense or perfect aspect marker and introduces Shirai $(2002$, p. 43) proposal that $-t a$ is grammatically developed from a perfect marker to a simple past tense marker.

5 Unlike English, Japanese, has no object-telicity marking mechanism because of limited plural marking and no article system (Slabakova 2008, p. 148). For example, the following sentence is unspecified for telicity: Yutaro-wa _hon_-o kari-ta. Yutaro-TOP book-ACC borrow-PERFECTIVE or PAST. 'Yutaro has borrowed or borrowed _book_[a/the/Ø̄ book (s)].' 
This suggests that the temporal and aspectual notions depend on an interaction of verbal inflection, the properties of the verb phrases, and other means (Olsen 1997; Smith 1991, 1997; Verkuyl 1993), as illustrated in Examples (4. a/b).
4
a. Yutaro-wa moo
Yutaro-TOP already three-CL
san-satu
hon-o
kari-ta.
book-ACC
borrow-PERFECTIVE
'Yutaro has already borrowed three books.'
b. Yutaro-wa sanjyu-pun-de ni-satu hon-o yon-da.
Yutaro-TOP 30 minutes-in two-CL book-ACC read-PERFECTIVE
'Yutaro has read two books in 30 minutes.'

\subsection{Imperfective Aspect Marker: English be + -ing and Japanese - tei-ru}

An imperfective aspect marker exhibits distinctions in interpretation between English and Japanese, unlike the simple past tense marker. In English, $b e+-i n g$ denotes a single [+progressive] (ongoing/in progress), regardless of the lexical aspect (activity, accomplishment, achievement), as given in Examples (5. a-c).

\section{5. [+progressive]}
a. Yutaro is swimming.
b. Yutaro is swimming one kilometre.
c. The plane is arriving at the airport.
[Activity]
[Accomplishment]
[Achievement]

By contrast, Japanese -tei-ru changes its interpretation, depending on the lexical aspect of the verbal predicates to which it is attached. "With most accomplishment verbs and all activities", Japanese -tei-ru denotes [+progressive], as does English be + -ing (Slabakova 2008, p. 162), as given in Examples (6. a/b), where -tei-ru serves as an imperfective aspect marker.

\section{6. [+progressive]}
a. Yutaro-wa hon-o Yutaro-TOP book-ACC
yon-de-iru.
'Yutaro is reading a book.'
read-PROGRESSIVE [Activity]
b. Yutaro-wa iti-kiro oyoi-dei-ru.
Yutaro-TOP one kilo swim-PROGRESSIVE [Accomplishment]
'Yutaro is swimming one kilometre.'

With achievements, Japanese -tei-ru encodes [+resultative], where the 'imperfective' aspect marker denotes 'perfective' aspect (Examples 7. a-c). Sugaya and Shirai $(2007$, p. 5) clearly explain that a 'resultative state' "focus[es] on the duration of state as a result of the punctual action". 
7. [+resultative]

[Achievement]
a. Yutaro-wa himitu-ni
kizui-tei-ru.
Yutaro-TOP secret-ACC
discover-RESULTATIVE
'Yutaro has discovered the secret (and he is aware of it).'
b. Booru-ga oti-tei-ru.
Ball-NOM fall-RESULTATIVE
'The ball has fallen (and it is there).'
c. Hikooki-ga kuukoo-ni tui-tei-ru.
Plane-NOM airport-at arrive-RESULTATIVE
'The plane has arrived at the airport (and it is there).'

With stative verbs, Japanese $-t e i-r u$ also denotes [+resultative]. English stative verbs (e.g., know, understand) represent ([+stative], [+durative] and [+atelic]). By contrast, the Japanese counterparts (e.g., siru-'know'; wakaru-'understand') could be classified as achievement verbs (e.g., 'come to

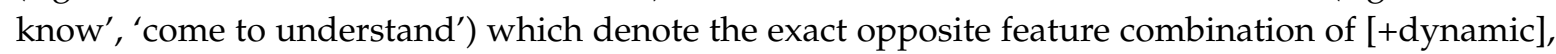
[+punctual], and [+telic]. The Japanese stative verbs thus necessitate -tei-ru (e.g., sit-tei-ru= 'know'; wakat-tei-ru = 'understand') to add "the duration of state" to "a result of the punctual action" (Sugaya and Shirai 2007, p. 5), as shown below (Examples 8. a/b).

8. [+resultative]

$[$ Stative $]=[$ Achievement $]$
a. Watashi-wa anata-o sit-tei-ru.
I-NOM you-ACC
know-RESULTATIVE
'I have got to know you (and I have known you since then).
b. Taro-wa kono riron-ga wakat-tei-ru.
Taro-TOP this theory-ACC understand-RESULTATIVE
'Taro has understood this theory (and he has a complete knowledge of this theory).'
(abridged and adapted from Tsujimura 2007, p. 384)

It should be noted that the Japanese imperfective aspect marker - tei-ru has another interpretation, by virtue of the interaction with adverbs/adverbial phrases. With verbs of any lexical aspect classes, -tei-ru allows [+habitual], as given in Examples (9. a/b) (Fujii 1996; Ogihara 1999; Sugita 2009).

9. [+habitual]
a. Watashi-wa maiasa
'I swim every morning.'
I-TOP every morning swim-HABITUAL
b. Watashi-wa maiasa iti-kiro oyoi-dei-ru. [Accomplishment] I-TOP every morning one kilometre swim-HABITUAL
'I swim one kilometre every morning.'

Unlike its Japanese counterpart -tei-ru, English $b e+-i n g$ is able to encode neither [+habitual] with accomplishment verbs and adverbial phrases (10. a), nor [+resultative] with achievement verbs (10. b), as explained above (Examples 5. a-c).
10. a. *Yutaro is swimming one kilometre every morning.
*[habitual+Accomplishment]
b. *Yutaro is discovering the secret.
*[resultative+Achievement] 


\section{The Feature Reassembly Hypothesis}

The Feature Reassembly Hypothesis (Lardiere 2008, 2009) attributes L2 morphological variability to different, language-specific behaviours and conditions in which morphosyntactic, semantic and phonological features are selected and assembled into morpholexical items. This suggests both a prominent role of L1 transfer in L2 developmental processes and a dissociation between underlying syntactic knowledge and inflectional morphology.

This hypothesis is framed within the Minimalist Program (Chomsky 2000, 2001, 2005) which shifted the focus from the setting of formal features to the configuration of the features on lexical items in functional categories. This assumes that: (1) human languages have a uniform computational mechanism; (2) language acquisition is characterised as two continuous processes of feature selection and assembly. This suggests that features come from the universal inventory for all languages but are selected and assembled in a language-specific way.

Lardiere (2009, p. 191) mentions that "a feature-reassembly approach follows and builds on FT/FA, by assuming the 'full transfer' part and attempting to further develop the 'full access' part", where L2 initial grammars are fully L1-transferred and the subsequent interlanguage grammars are UG-constrained. Lardiere suggests that L2 learners' initial analysis would be based on "the morpholexical equivalents" from "already-assembled lexical items" in L1 (Lardiere 2009, p. 213) and then their morphological competence ("the knowledge of precisely which forms go with which features") (Lardiere 2008, p. 111) would be acquired gradually through Universal Grammar (UG) ${ }^{6}$ interaction with L2 input. In addition, the FRH proposes that feature reassembly can be a source of persistent difficulty for L2 speakers, although "any feature contrast that is detectable is, in principle, ultimately acquirable" (Lardiere 2009, p. 214). Lardiere (2009) assumes that L2 learners will struggle most with reassembling features which exist in their own L1 but are configured and/or expressed in a different way, and that this may be dependent upon differences in context. This suggests that it might be more challenging for L2 learners to delearn already-assembled lexical items in the L1 than to learn the selection of new features or the assembly into new lexical items in the L2.

It should be noted that two assumptions underlie the FRH, as mentioned above. First, two L2 learning tasks are assumed (Example 11), based on Chomsky's two processes. L2 learners have to reselect features and repackage the selected features into L2-specific morpholexical items.

11. Two learning tasks in L2 acquisition (F: features/ML: morpholexical items)
1. Feature Selection
$\left[\mathrm{F}_{\mathrm{L} 1}\right] \quad \rightarrow \quad\left[\mathrm{F} \mathrm{L}_{2}\right]$
2. Feature Assembly
$\left[\mathrm{ML} \mathrm{L1}_{\mathrm{L}} \rightarrow[\mathrm{ML}\right.$ L2]

Second, three determinants of learnability are assumed in the L2 acquisition processes (12).

12. Three determinants of L2 learnability
1. Same Features
$\left[\mathrm{F}_{\mathrm{L} 1}\right]=\left[\mathrm{F}_{\mathrm{L} 2}\right]$
2. Different Configurations
$\left[\mathrm{ML} \mathrm{L}_{1}\right] \neq\left[\mathrm{ML}_{\mathrm{L} 2}\right]$
3. Morpholexical Correspondences $\left[\mathrm{ML} \mathrm{L1}_{1}\right] \Leftrightarrow\left[\mathrm{ML} \mathrm{L2}_{2}\right]$

Considering the three determinants of learnability, L2 learners are less likely to produce appropriate morphology if features exist in both L1 and L2 but the features are configured differently. By contrast, it may be easier for them to reassemble L1 features into L2 morpholexical items if there are "fewer formal differences and more straightforward (morpho)lexical correspondences" (Lardiere 2009, p. 188). This suggests that L1-L2 contrasts could determine ease or difficulty of the two L2 learning tasks.

6 The principles of language structure which are innately present. 
Table 3 encapsulates the two learning tasks (1. Feature Selection; 2. Feature Assembly) and the three determinants of learnability (1. Same Feature; 2. Different Configuration; 3. Morpholexical Correspondences) for Japanese leaners of English. For the past-tense marker, Japanese $\left(\mathrm{F}_{\mathrm{L} 1}\right)$ and English $\left(\mathrm{F}_{\mathrm{L} 2}\right)$ share both the same feature [+past] $\left(\mathrm{F}_{\mathrm{L} 1}=\mathrm{F}_{\mathrm{L} 2}\right)$ and morpholexical correspondence $\left(\mathrm{ML}_{\mathrm{L} 1}\right.$ $\left.\Leftrightarrow M L_{L 2}\right)$. By contrast, for the non-past tense and imperfective aspect markers, they select the same features $\left(\mathrm{F}_{\mathrm{L} 1}=\mathrm{F}_{\mathrm{L} 2}\right)$ but share neither the same configurations $\left(\mathrm{ML}_{\mathrm{L} 1} \neq \mathrm{ML}_{\mathrm{L} 2}\right)$ nor morpholexical similarities $\left(\mathrm{ML}_{\mathrm{L} 1} \Leftrightarrow \mathrm{ML}_{\mathrm{L} 2}\right)$. To summarise the differences discussed in detail above: Japanese has a single non-past tense form -ru to denote [-past] with any phi-features, while English has the two forms with the different combinations of phi-features; the Japanese imperfective form -tei-ru is associated with three aspectual features ([+progressive], [+habitual], and [+resultative]), while English $b e+-i n g$ encodes only a [+progressive] feature. Under the FRH, it is predicted that L1 Japanese learners will easily be able to reassemble [+past] into an L2 item $-e d$, whereas they will have to realise the three specified features on a single new lexical item $-s$ and reconfigure only one feature [+progressive] into a pair of L2 item be +- ing.

Table 3. L2 learning tasks and determinants of L2 learnability.

\begin{tabular}{|c|c|c|c|c|c|c|c|}
\hline & \multicolumn{2}{|l|}{$\begin{array}{l}\text { 1. Feature } \\
\text { Selection }\end{array}$} & Det.1 & \multicolumn{2}{|c|}{$\begin{array}{l}\text { 2. Feature } \\
\text { Reassembly }\end{array}$} & Det.2 & Det.3 \\
\hline & $\mathrm{F}_{\mathrm{L} 1} \quad \Rightarrow$ & $\mathrm{F}_{\mathrm{L} 2}$ & $\mathrm{~F}_{\mathrm{L1}}=\mathrm{F}_{\mathrm{L} 2}$ & $\mathbf{M L}_{\mathbf{L 1}} \Rightarrow \mathbf{N}$ & & $\mathbf{M L}_{\mathbf{L} 1} \neq \mathbf{M L}_{\mathbf{L} 2}$ & $\mathbf{M L}_{\mathbf{L} 1} \Leftrightarrow \mathbf{M L}_{\mathbf{L} 2}$ \\
\hline \multirow{3}{*}{ Tense } & {$[+$ past $]$} & {$[+$ past $]$} & (2) & $-t a$ & $-e d$ & $X$ & (2) \\
\hline & $\begin{array}{l}\text { [-past] } \\
\text { [1st } \\
\text { person] } \\
\text { [2nd } \\
\text { person] } \\
\text { [-singular] }\end{array}$ & $\begin{array}{l}\text { [-past] } \\
\text { [1st } \\
\text { person] } \\
\text { [2nd } \\
\text { person] } \\
\text { [-singular] }\end{array}$ & \multirow[t]{2}{*}{ (a) } & \multirow[t]{2}{*}{$-(r) u$} & $-\varnothing$ & (0) & $X$ \\
\hline & \begin{tabular}{l}
\multicolumn{1}{c}{-} \\
[3rd \\
person] \\
[+singular]
\end{tabular} & $\begin{array}{l}\text { [-past] } \\
{[3 \mathrm{rd}} \\
\text { person] } \\
\text { [+singular] }\end{array}$ & & & $-s$ & (0) & $X$ \\
\hline \multirow{3}{*}{ Aspect } & \multicolumn{3}{|c|}{ [+progressive $][+$ progressive $]$} & \multirow{3}{*}{$-t e i-r u$} & be+ - ing & (0) & $X$ \\
\hline & [+habitual] & [+habitual] & (0) & & $-\varnothing /-s$ & (0) & $x$ \\
\hline & \multicolumn{3}{|c|}{ [+resultative] [+resultative] } & & have $+-e n$ & (0) & $X$ \\
\hline
\end{tabular}

Key: Det. (determinant): Det.1 = same features; Det.2 = different configurations; Det.3 = morpholexical correspondences; ${ }^{(0)}=$ applicable; $X=$ not applicable to each determinant (Det.1-3).

Lardiere (2009) discusses the learning tasks in the L2 acquisition of plural marking in English, Chinese, and Korean. All the three languages share the same [+plural] feature but the different configurations and the various conditions under which plural marking occurs. In English, [+plural] is combined with $[ \pm$ human] $/[ \pm$ definite] and agrees with quantifiers denoting plurality (e.g., six students, several students, and both students, (Lardiere 2008, p. 122). In Chinese, on the other hand, [+plural] is represented only by suffix $-m e n$, which allows only two features [+human]/[+definite] and also prohibits co-occurrence with quantifiers (e.g., *san-ge xuesheng-men 'three-CL student-PL', (Lardiere 2009, p. 196). ${ }^{7}$ Given the differences between English and Chinese, English speakers of L2 Chinese are "initially likely to overgeneralize the applicability of plural marking [to Chinese - men]" (Lardiere 2009, p. 198), whereas Chinese speakers of L2 English are likely to fail to produce plural markers due to the optionality of Chinese plural marking. This suggests that L1 English speakers

7 Following Li (1999, p. 87), such impossibility of qualified plural nouns in Chinese is attributed to the phenomenon that "a Classifier head (e.g., san-ge 'three-CL') intervenes between $\mathrm{N}$ and D", which allows no raising of noun (e.g., xuesheng 'student') to Number for checking [+plural], and further to Determiner for checking [+definite] (Lardiere 2009, p. 196). 
would need to reassemble [+plural] with [+definite ${ }^{8}$ into an L2 Chinese plural suffix -men, whereas L1 Chinese speakers would need to learn the obligatoriness of plural marking and extend co-occurrence with [-human]/[-definite] and quantifiers (Lardiere 2008, p. 123).

In Korean, the plural suffix - tul has more complicated distribution than in English and Chinese. Korean has two types of plural marking that appears optionally under certain restricted conditions. In 'extrinsic' plural marking, "if a subject is pluralised, the morpheme - tul may also optionally spread to various other constituents that are c-commanded by that subject within the same clause" (Lardiere 2009 , p. 205). In 'intrinsic' plural marking, plural marker - tul is directly attached to a noun. For English learners of L2 Korean, the intrinsic plural marking is more similar to English plural marking in terms of the features, while the extrinsic plural marking has no morpholexical correspondence. Lardiere (2009) points out that the reassembly of a Korean plural marker - tul requires English speakers of L2 Korean to discern not only different co-occurring features under different conditions but also multiple interpretations of lexical semantic features.

\section{Previous L2 Studies}

\subsection{Previous Studies on L2 English Verbal Morphology}

In the previous studies of L2 English verbal morphology, Ionin and Wexler (2002, pp. 106, 107, $109)^{9}$ and Goad et al. $(2003 \text {, pp. } 255,256)^{10}$ shared the same accuracy sequence (copula be $>$ auxiliary be $>$ irregular past forms $>$ regular past $-e d>3 S G-s)$, as shown in Figure 1.

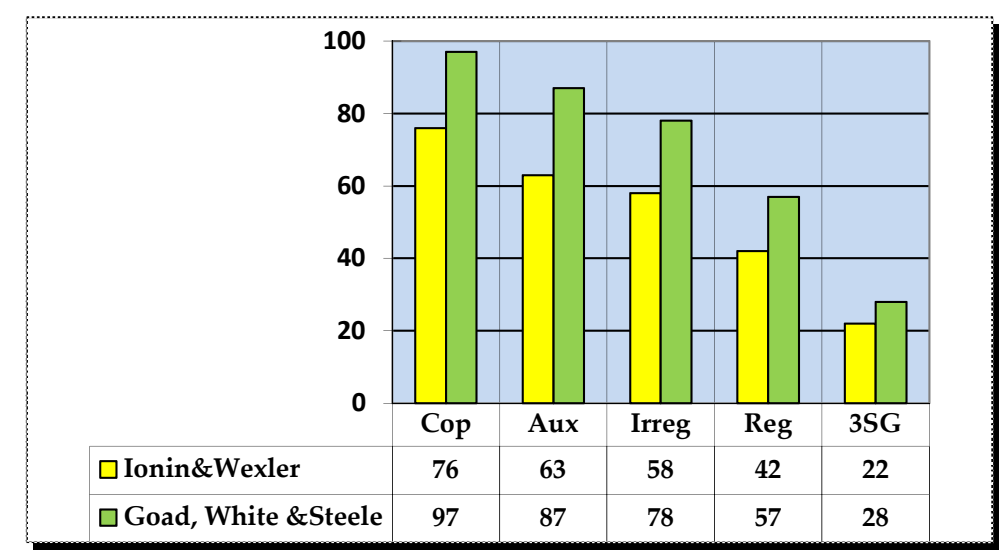

Figure 1. Accuracy rates of English verbal morphology in obligatory contexts (\%).

Another L2 English study (Haznedar 2001) showed similar results, despite a different sequence with $3 S G-s$ being more accurate than regular past - ed (copula be $96.43 \%>$ auxiliary be $75.92 \%>$ irregular past $40.59 \%>3 S G-s 46.67 \%>$ regular past - ed 26.65\%). In the study of Geçkin and Haznedar (2008, p. 246, 254), the spontaneous production data from three Turkish-speaking children shared the similarity (copula be $>(3 S G-s)>$ irregular past $>$ regular past $-e d>(3 S G-s)^{11}$ : $(1)$ copula be was supplied higher than the three affixal morphemes; (2) irregular past forms are supplied higher than regular past $-e d$. All the accuracy orders are consistent with the findings that suppletive morphology

8 In English, the [+definite] feature is realised on the definite article the, not on the plural suffix $-s$.

9 The figures shown here are from the results of a free story-telling task (spontaneous production data), similar to those of Hawkins and Casillas (2008, p. 596).

10 Auxiliary includes be, do, and have.

11 There was no result of auxiliary be. Only the results of 3SG $-s$ varied, depending on the subject as follows: Nil: $\quad$ copula be $97.65 \%>3 S G-s 66.67 \%>$ irregular past $63.84 \%>$ regular past - ed $56.98 \%$ Ayda: $\quad$ copula be $92.31 \%>$ irregular past $48.25 \%>$ regular past $-e d 28.32 \%>3 S G-s 20.13 \%$

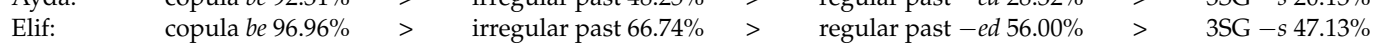


(copula and auxiliary be) are produced much more easily and accurately than affixal morphology on lexical verbs (White 2008), regardless of differences in age, L1 background, and length of English exposure (Table 4).

Table 4. Previous L2 English studies (naturalistic spoken data).

\begin{tabular}{ccccc}
\hline & Age & L1 Background & Length of Exposure & Number of Participants \\
\hline Ionin and Wexler (2002) & $3 ; 9-13 ; 10$ & Russian & $\begin{array}{c}\text { below 1 year } \\
1-3 \text { years }\end{array}$ & 20 \\
\hline Goad et al. (2003) & adults $^{12}$ & Chinese & 6 months to 5 years & 12 \\
\hline Haznedar (2001) & 4 & Turkish & 1.5 months & 1 \\
\hline $\begin{array}{c}\text { Geçkin and Haznedar } \\
\text { (2008) }\end{array}$ & $4 ; 5$ & Turkish & 1 year & 3 \\
\hline
\end{tabular}

\subsection{Previous Studies on the Role of L1 in the Acquisition of L2 Tense-Aspect Morphology}

There are numerous studies that have investigated the effects of the L1 on the L2 acquisition of tense-aspect morphology. Some studies have specifically examined L1 Japanese learners of English and various L1 learners of L2 Japanese, focusing on the differences in aspectual semantics of the imperfective markers be + -ing and -tei-ru (Gabriele 2008; Sugaya and Shirai 2007).

Sugaya and Shirai (2007) aimed to explore why the inherent (lexical) aspect of verbs influences the acquisition of grammatical aspect markers, by addressing three research hypotheses: (1) the effects of the L1 (the presence or absence of a progressive marker) on the acquisition of the two basic meanings of $-t e i-r u$ (progressive and resultative states): (2) the influence of inherent aspect on the acquisition of the progressive meaning of $-t e i-r u$ : (3) the influence of inherent aspect on the choice of alternative forms. They examined eighty adult learners (aged 19-53) of L2 Japanese: thirty-nine L1 English speakers and forty-one speakers whose languages do not have obligatory progressive markers $^{13}$. There were two kinds of tasks employed. An acceptability judgement task, administered to only seventy-one intermediate and advanced learners of L2 Japanese, examined whether they could choose the most appropriate form from the four finite verb forms (non-past $-(r) u$, past $-t a$, non - past imperfective $-t e i-r u$, past imperfective $-t e i-t a)$, judging from the context in a short dialogue. The $-t e i-r u$ contexts include both progressive and resultative state meanings. The targeted context of a sample test item (Sugaya and Shirai 2007, p. 35, Appendix A) is a resultative state, as given below (13).

13. Romanised version and gloss ${ }^{14}$
Takahashi:
Are, syatu-ni kutibeni (lipstick)-ga
Oh, shirt-LOC lipstick-NOM
ne.
"Oh, there's lipstick on your shirt." -FP.
Yamamoto:
E, hontoo desu-ka!?
Oh, true-COP-Q !?
"Oh, really!?"

$\begin{array}{llll}\begin{array}{l}\text { A. tukimasu } \\ \text { attach: NONPAST }\end{array} & \begin{array}{l}\text { B. tukimasita } \\ \text { attach: PAST }\end{array} & \begin{array}{l}\text { C. tuiteimasu } \\ \text { attach: IMP-NONPAST }\end{array} & \begin{array}{l}\text { D. tuiteimashita } \\ \text { attach: IMP-PAST } \\ \text { "was attached" }\end{array} \\ \text { "has been attached" } & \text { "had been attached" }\end{array}$

An oral picture description task, on the other hand, was to examine whether the two L1 learner groups of L2 Japanese would be able to distinguish the two meanings of -tei-ru, by orally describing

12 There is no detailed description of the subjects.

13 Eighteen German, eighteen Russian, three Ukrainian, and two Bulgarian (Sugaya and Shirai 2007, p. 12).

$14 \mathrm{FP}=$ final particle, IMP = imperfective aspect marker (Sugaya and Shirai 2007, p. 36). 
the differences between the two pictures for ten minutes. All eighty learners participated in the task but only the data collected for intermediate and advanced learners were analysed to compare those of the acceptability judgement task. The results revealed: (1) only lower L1 groups in the oral task showed the L1 effects on the acquisition of the two meanings of -tei-ru: (2) learners in the judgement task showed a strong association between the lexical aspect of verbs and the acquisition of the progressive marker, by having a much higher score for activity verbs $+-t e i-r u$ than the other verb types (accomplishments or semelfactives); (3) learners in both tasks showed the influence of lexical aspect of verbs, by choosing the past tense marker - $t a$ as an alternative form for achievements. It is concluded that not only L1 transfer but also multiple factors (i.e., task types and proficiency) affect the association between the lexical aspect and the acquisition of tense-aspect marker.

Gabriele (2008) investigated whether L2 learners can unlearn their L1 interpretations that are not available in the L2. This is a bidirectional study of L2 learners between English and Japanese, by investigating their respective interpretations of English $(b e+-i n g)$ and Japanese $(-t e i-r u)$ imperfective aspect markers. First, the bidirectional study examined two groups of Japanese speakers of L2 English: (1) a total of 101 Japanese young instructed learners with three levels of proficiency (low/intermediate/advanced); (2) nine "near-native candidates" of L2 English (Gabriele 2008, p. 381) who had lived in New York City for seven years on average. In a story compatibility task where two lexical aspect of verbs (accomplishments and achievement) were tested, the participants were asked to decide which type of the test sentence (e.g., either past or present progressive) was compatible with each of the two contexts (complete and incomplete story contexts) that were first presented with a picture and the narration of a few sentences. They were asked to choose a scale of 1 to 5: for example, ' 1 ' means "I definitely cannot say this sentence in the context of the story" (Gabriele 2008, p. 382). An example of an achievement verb (arrive) is shown below, where the complete story context is called 'preemption' context and the incomplete story context 'addition' context respectively. In the preemption context (14a), L1 Japanese leaners of L2 English must reject the sentence including be + - ing in the complete context. It is predicted that even advanced learners may have difficulty interpreting correctly. On the other hand, in the addition context $(14 \mathrm{~b})$, they must accept the sentence including $b e+-i n g$ in the incomplete context. It is predicted that Japanese learners "will have less difficulty overcoming transfer" (Gabriele 2008, p. 384).

14. (7) Arrive (achievement)

Picture 1: This is the plane to Tokyo. At 4:00 the plane is near the airport.

a. Complete story context (preemption)

Picture 2a: At 5:00 the passengers are at the airport.

i. Past: The plane arrived at the airport.

(Expected rating of NSs: 5; L2 English learners: 5)

ii. Present Progressive: The plane is arriving at the airport.

(Expected rating of NSs: 1; L2 English learners: 5)

b. Incomplete story context (addition)

Picture 2b: There is a lot of wind. At 4:30 the plane is still in the air.

i. Past: The plane arrived at the airport.

(Expected rating of NSs: 1; L2 English learners: 1)

ii. Present Progressive: The plane is arriving at the airport.

(Expected rating of NSs: 5; L2 English learners: 1)

The results demonstrated a difference between accomplishments and achievements, as predicted. With accomplishments (e.g., paint a portrait, make a cake, write a book, build a sandcastle), all proficiency groups successfully accepted the progressive (is painting a portrait) in the incomplete context and the past (painted a portrait) in the complete context by choosing ' 5 '. On the other hand, with achievements (e.g., arrive, die, come, return), the advanced group performed more accurately than the other two 
groups only in the addition context: individual analyses found that "even some advanced learners" (Gabriele 2008, p. 387) failed to reject the progressive form in the complete context (preemption). This suggests that L1 Japanese learners have difficulty in ruling out their interpretation of the imperfective marker $-t e i-r u$ for achievements (is arriving $\rightarrow t u i-t e i-r u$ : completion in Japanese).

Second, the bidirectional study investigated thirty-three young English speakers of L2 Japanese with the exposure to Japanese ranging from six months to six years. The participants, divided into two groups (low/high proficiency) were similarly asked to judge the test sentences in the compatibility story task in Japanese. Like L2 English learners, L2 Japanese learners performed accurately on accomplishments, as predicted. With achievements, all groups were successful in the addition contexts, whereas the low-proficiency group failed to reject the imperfective marker -tei-ru in the incomplete context (preemption). L1 English learners of L2 Japanese also have difficulty in unlearning their interpretation of the imperfective marker be $+-i n g$ for achievements $(t u i-t e-i r u \rightarrow$ is arriving: incompletion in English).

The overall results indicated that "it was more difficult for the L2 English learners, with preemption presenting the greatest challenge." (Gabriele 2008, p. 394). Both L2 English and Japanese learners performed accurately on accomplishments, as predicted, whereas neither of the L2 learner groups did successfully on the preemption contexts for achievements. More specifically, for L2 English learners, all groups failed in the preemption context; for L2 Japanese learners, only the low-proficiency group failed in the preemption. Gabriele explains why Japanese learners of L2 English face a greater challenge than English learners of L2 Japanese. First, they need to learn that "achievements require a semantic type-shifting to repair the aspectual mismatch between the VP and the progressive operator" (Rothstein 2004; Gabriele 2008, p. 395). Second, it is more difficult for L1 Japanese learners to "distinguish the preparatory stages (e.g., the train approaching) from the point of culmination (e.g., the train at the platform)" (Gabriele 2008, p. 397). In other words, in these cases, the absence of restructuring of L2 grammar can lead them to preempt an L1 option (i.e., 'the train is arriving' in the complete context). It should be assumed that Japanese learners are likely to misinterpret 'is arriving' as resultative tui-tei-ru (e.g., the train has arrived and is here) (see Example 7 in Section 2.2).

\section{Study}

\subsection{Research Question and Predictions}

Based on the FRH's key assumptions (see Section 3), the present study aims to address a research question of how L1-L2 contrasts in feature selection and assembly would be a potential cause of morphological variability in L2 acquisition. Specifically, the research question asks whether the different configurations of the features shared by L1 and L2 will impede the successful production of inflectional morphology and if L1-L2 morpholexical correspondences would facilitate L2 learning processes. Under the FRH, it is predicted that:

(1) L2 Japanese learners will easily be able to reassemble [+past] into an L2 item -ed.

(2) L2 Japanese learners will have more difficulty in realising an unfamiliar composition of [-past] with [3rd person] [+singular] on a single new morpholexical form $-s$.

(3) L2 Japanese learners will face even more of a challenge in reconfiguring only one feature [+progressive] into a pair of L2 items be + -ing.

\subsection{Participants}

The participants were 132 L1 Japanese speakers, who were adolescent learners of English and who had received formal instruction in a classroom setting, as summarised in Table 5. 
Table 5. Participants.

\begin{tabular}{|c|c|c|c|c|c|c|}
\hline \multicolumn{2}{|c|}{ Grade/Year } & Age & Number & $\begin{array}{l}\text { L2 Data } \\
\text { Mode }\end{array}$ & $\begin{array}{c}\text { Years of English } \\
\text { Study }\end{array}$ & $\begin{array}{c}\text { Hours of English } \\
\text { Class }\end{array}$ \\
\hline \multirow{3}{*}{$\begin{array}{l}\text { Junior High } \\
\text { (CEFR A1) }\end{array}$} & $1 s t$ & $12-13$ & $\begin{array}{l}30 \\
12\end{array}$ & $\begin{array}{l}\text { Written } \\
\text { Spoken }\end{array}$ & 8 months & $\begin{array}{l}160 \\
160\end{array}$ \\
\hline & 2nd & $13-14$ & 30 & \multirow{3}{*}{ Written } & 1.8 years & 360 \\
\hline & 3rd & $14-15$ & 30 & & 2.8 years & 560 \\
\hline $\begin{array}{l}\text { University } \\
\text { (CEFR B1) }\end{array}$ & 2nd & $19-20$ & 30 & & 7.8 years & 1560 \\
\hline
\end{tabular}

CEFR (Common European Framework of References for Languages). ${ }^{15}$

The participants were from two integrated junior-senior high schools and one university in Japan, where children typically started receiving formal English teaching from the first grade of junior high school. A total of ninety junior high school students from the first to third grade were tested, with the aim of observing 'gradual development', corresponding to an early stage of learning (the first grade) and subsequent developmental stages (the second and third grade) in the acquisition of L2 English. The experiment was carried out ${ }^{16}$ when the first-grade junior high school students had had eight months of exposure to English, because L2 learners in the earliest stages of acquisition are assumed to go through 'a silent period' which usually takes around six months. ${ }^{17}$ The first and third grade students for the written task were from one school, while the second grade for the written task and the first grade for the spoken task were from a different school. The second-year university students were selected as being representative of later development for comparison with the junior high school students. The university students are assumed to be in neither the L2 initial nor end state, given the total number of English class hours. This study had no control group because the properties examined are uncontroversially core properties of English in simple declarative or interrogative sentences that fifteen British native speakers performed at ceiling in the pilot study ${ }^{18}$. The participant groups in the present study were chosen on the basis of the number of years of English study.

To ensure a similarity in proficiency level within the same group, two complementary measures were taken. For junior high students, the linguistic background questionnaire was conducted to exclude those who had received intensive, regular, and long-term English education in either Japan or English-speaking countries before and after entering junior high schools. For university students, a TOEIC score was used, where only students with scores between 650 and 680 were analysed. The hours of English class exposure in this study were calculated based on the total hours of instruction per week by number of teaching weeks in the academic year ${ }^{19}$. In Japan, for the junior high school students, the same grade suggests the same total number of English class hours, while for the university students who attended a compulsory TOEIC (Test of English for International Communication) ${ }^{20}$ course scheduled in the second year with the same non-English related major, the addition of the

15 Japanese junior high school students and university students fall into CEFR A1 and B1 respectively, based on the classification made by an advisory panel related to the Ministry of Education, Culture, Sports, and Technology.

16 Primary School English language teaching was formally introduced in Japanese elementary schools (the fifth and sixth grades) in April 2011, which was after the experiment was finished in February 2011.

17 Grüter and Conradie (2006, p. 90) point out that in early production data it is hard to distinguish 'absence of evidence' (common and frequent failure to realise grammatical knowledge) from 'evidence of absence' (impaired grammar); White (2003b, p. 75) raises a falsifiability problem and assumes that it might be impossible for production data to investigate whether the earliest stages before the emergence of L2 speech lack functional categories or not.

18 White $(2003 \mathrm{~b}$, p. 55,56$)$ suggests that "the crucial question is whether or not interlanguage grammars are UG-constrained, rather than whether or not they are native-like".

19 Five hours per week $\times 40$ weeks $=200$ hours per year: eight weeks were excluded due to holidays (summer, winter and spring).

20 The TOEIC reading and listening test is regarded as a reliable and standard measure to assess non-native English proficiency: because the test: (1) began in 1979 and is currently used over sixty countries and taken by 4.5 million people per year; (2) requires the candidate to answer 200 multiple-choice questions in two hours; (3) is scored from ten to 990 with no pass-fail mark. The TOEIC score sheet shows only the total score of reading and listening sections (e.g., Total 750: Listening 350/Reading 400). 
same 'age' to the same 'university year' was necessary to ensure similarity in the number of English class hours ${ }^{21}$.

\subsection{Materials}

It was decided that, for the main study, a picture-stimulus elicited production task would be the best single method to test the linguistic knowledge that early stage and developmentally more advanced learners have, considering both the impossibility of doing more than one task ${ }^{22}$ and the issues identified in the pilot task. ${ }^{23}$ The production task consisted of sixty-three question items to concentrate on two types of morphological production (verbal and nominal morphology) and three syntactic operations (main verb placement, overt subjects with nominative case marking, $w h$-movement). Table 6 illustrates ten obligatory contexts of verbal morphology in both suppletive (copula and auxiliary be) and affixal morphemes (regular past $-e d /$ irregular past form/3SG $-s$ ) examined in the current study. Each morpheme tested had six/nine tokens.

Table 6. Obligatory contexts of verbal morphology.

\begin{tabular}{|c|c|c|c|c|}
\hline & Morphemes & Tokens & Obligatory Contexts & Examples (Item Numbers) \\
\hline \multirow{4}{*}{ Suppletive } & \multirow{3}{*}{ Copula } & 3 & Affirmative $+\varnothing$ & He is happy today (No. 5). \\
\hline & & 3 & Negative & She isn't angry (No. 55). \\
\hline & & 3 & Affirmative $+\mathrm{VP}-$ adverbs & He is always busy at work (No. 59). \\
\hline & \multirow[t]{2}{*}{ Auxiliary } & $\begin{array}{l}3 \\
3\end{array}$ & Affirmative & She is eating breakfast now (No. 8). \\
\hline & & & & \\
\hline \multirow{6}{*}{ Affixal } & \multirow{2}{*}{ Regular-ed } & 3 & Affirmative $+\varnothing$ & He watched TV yesterday (No. 10). \\
\hline & & 3 & Affirmative $+\mathrm{VP}-$ adverbs & She often played the piano last year (No. 2). \\
\hline & \multirow{2}{*}{ Irregular } & 3 & Affirmative $+\varnothing$ & He went to school yesterday (No. 43). \\
\hline & & 3 & Affirmative $+\mathrm{VP}-$ adverbs & He often ate cake last year (No. 58 ). \\
\hline & \multirow{2}{*}{ 3SG-s } & 3 & Affirmative $+\varnothing$ & He likes sweets (No. 27). \\
\hline & & 3 & Affirmative $+\mathrm{VP}-$ adverbs & She usually eats breakfast at nine (No. 18). \\
\hline
\end{tabular}

The test items needed to introduce no additional distractors because they required participants to produce responses that involved affirmative, negative and interrogative clauses, main and copula/auxiliary verbs, present and past tenses, where the different clause and phrase types acted as distractors for each other.

An introductory practice test was created to familiarise participants with the kinds of answers they needed to give, with written Japanese instructions on how they were to answer all of the question items, as shown below (Example 15).

21 Japanese university students in the same year include students of different age who have received additional English teaching for a year or more to take an entrance exam again.

22 The junior high schools set the time limit because junior and senior high schools in Japan are bound by a tightly-managed curriculum, which allowed only one kind of task to be carried out.

23 A combination of three tasks was piloted with eighty-seven second grade junior high school students and fifteen British speakers in 2006: (1) an eighty-item translation task; (2) a thirty-three-item grammaticality judgement task; (3) a thirty-two-item picture-interpretation task. The overall results showed too high accuracy rates (90\% to $98.7 \%)$. The results revealed that it was difficult to explore the nature of early L2 leaners' unconscious competence in the comprehension-based tasks that allow them to use metalinguistic knowledge. 
15.

例題(Practice test items)

1. 栄作は昨夜ビーフシチューを食べましたか。

Did Eisaku eat beef stew last night?

(Answer)

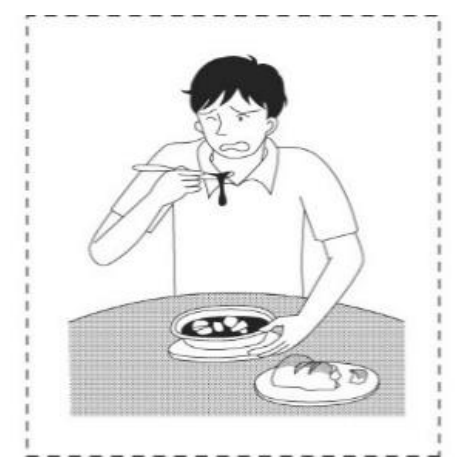

No. beef stew, last night $\Rightarrow$ (答え) He didn't eat beef stew last night.

(Answer)

Each item consisted of a Japanese question sentence, a picture, and between one and three English words to help the participants write or speak an English answer. The actual test had no English glosses or the target sentences that the English stimulus words were intended to elicit, both of which are added here only for the purposes of illustration, as given in an actual test item below.

16.

18. 小百合は朝どうしていますか?

'What does Sayuri do in the morning?'

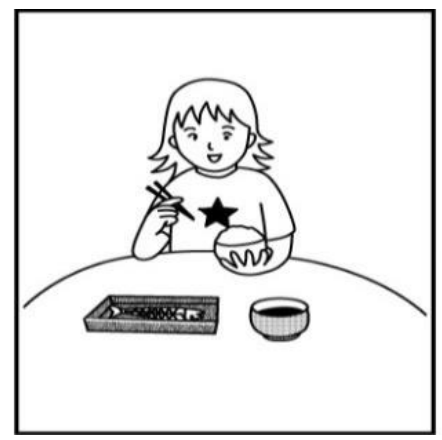

nine, usually, breakfast [An expected answer] She usually eats breakfast at nine.
(答え)

'Answer'

\subsection{Procedure}

The procedure in this study was adopted to deal with problems that were encountered in the pilot study ${ }^{24}$, where the participants, regardless of the number of English class hours, showed a strong tendency to either write/say nothing at all, or revise/repeat each of their productions again and again, only when they felt uncertain about the meanings of the English prompt words and the spelling/pronunciation/grammaticality of their own answers. As a result, many of them used up all the allocated time in answering only the first few questions, by either getting stuck on a single item, or by reviewing their answers over and over. Furthermore, by taking so much time, they are likely to be appealing to metalinguistic knowledge, obscuring patterns of response that might be indicative of the real state of their competence. Therefore, written and spoken instructions were provided to prevent them from reconsidering their answers many times.

24 The picture-stimulus task for this study was piloted with four first-grade junior high students (three for written and one for spoken) and twenty-three second-year university students (written only). 
First, to get rid of the obsession with correctness that Japanese students tend to have, they were explicitly instructed to: (1) write or say whatever they first thought of, without worrying about the results; (2) neither revise their writing by using an eraser nor repeat what they said, because revised answers would not be scored. Second, to prevent participants from getting stuck on the meaning or spelling of English stimulus words, they were not only given Japanese translations of ten English words ( $12.3 \%$ of the total stimulus words) but also informed that both spelling errors and the use of Japanese Katakana ${ }^{25}$ were allowed in the written task. Finally, to prevent participants from drawing on their metalinguistic knowledge and to ensure that they provided answers to all of the test items, they were informed of the time they had taken at five-minute intervals, during which they were required to respond to ten test items.

\subsection{Scoring Criteria}

In scoring the data collected from the test instrument, sentences with correct word orders were only scored: those with faulty word orders were unscored as 'gap'. Aspect-tense marking was given either 1 (for the expected form) or 0 (for other unexpected forms or omission). In addition, both cases with the expected verbal inflection were also given a score of 1 , regardless of the use of: (1) a different main verb with similar meaning (17. a); (2) an unexpected subject (17. b).
17. a. He woke up at seven yesterday. (He got up at seven yesterday.) ---1 point for verbal morphology
b. I'm happy today. (He is happy today).
---1 point for verbal morphology
[JH1st No.2, Written]
[JH2nd No.11, Written]

However, in the case that an unexpected but similar-meaning main verb took a different past form (e.g., an irregular past form made) from that of the expected main verb (e.g., a regular form cooked), it was not scored, because the focus of the analysis was on affixal past tense inflection.

\section{Results}

\subsection{Accuracy Rates of Tense-Aspect Morphology}

The current study found an accuracy sequence, with regular past tense $-e d$ and auxiliary be reversed: copula be $>$ regular past $-e d>$ irregular past forms $>$ auxiliary be $>3 S G-s$, which were different from those of previous L2 studies (see Figure 1 in Section 4). In Figure 2, all participant groups showed the same accuracy sequence, except for Junior High $(\mathrm{JH})$ second-year and University groups, where irregular past forms were less accurate than auxiliary be. Two-way ANOVA (Participant Groups: JH first (written)/JH first(spoken)/JH second/JH third/Uni second $\times$ Verbal morphology: cop.be/reg.past $-e d /$ irreg. past/aux.be/3SG $-s$ ) reveals that the main effects between the five groups and between the five verbal morphemes are statistically significant respectively (Groups: $\mathrm{F}(4,123)=68.60, p<0.001$; Morphemes: $\mathrm{F}(4,123)=221.24, p<0.001)$. In addition, the interaction effect between the participant groups and the verbal morphemes is statically significant $(F(16,123)=94.70$, $p<0.001)$. The simple main effect for the participant groups and the individual morphemes is statistically significant $(p<0.001)$ and multiple comparisons by Holm method show a statistical significance $(p<0.005)$ between the groups, except for several group pairs. On the other hand, the simple main effect for the verbal morphemes and the individual groups is statistically significant $(p<0.001)$ and multiple comparisons by Holm method show a statistical significance $(p<0.005)$ between all morphemes.

25 Katakana is used to write loan words mainly from English. Katakana, like hiragana, represents forty-six symbols that consist of a single vowel (e.g., オ $=0$ ) and a pair of a consonant and a vowel (e.g., $タ=$ ta) (e.g., タオル = ta-o-ru 'towel'). They are both syllabaries (Iwasaki 2013). 


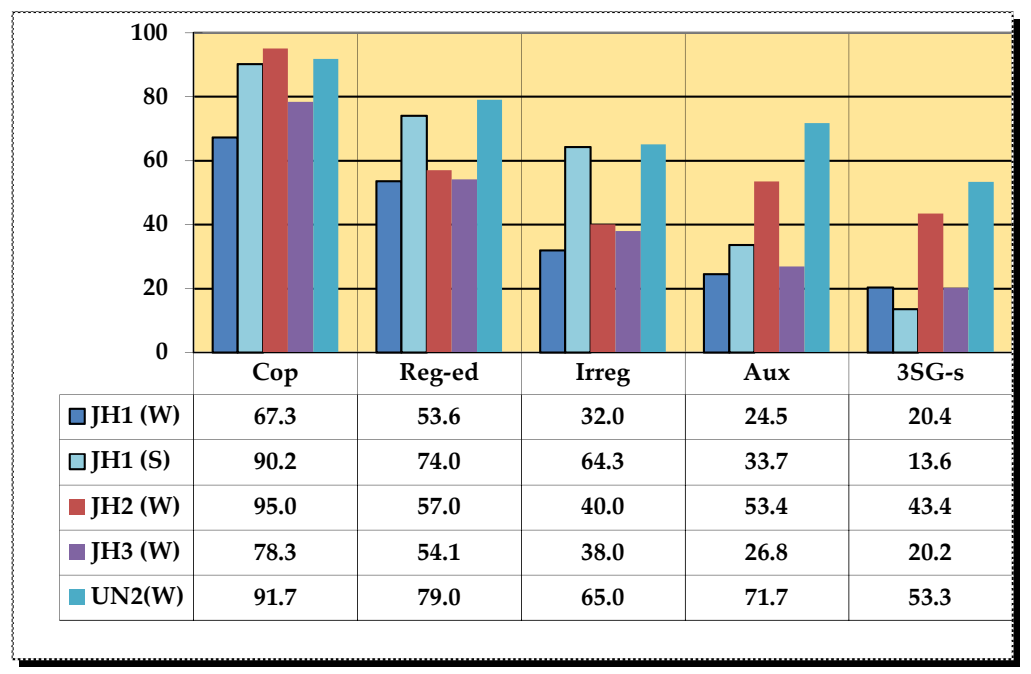

Figure 2. Accuracy rates by participant groups in obligatory affirmative with and without $\mathrm{VP}-$ adverb contexts (see Table 6) (\%).

Figure 3 shows the mean percentage for accuracy of each verbal morpheme, where Japanese young instructed learners demonstrated a clearly different performance in terms of tense (regular past $-e d$ ) and aspect (auxiliary be) morphology, regardless of production tasks in obligatory contexts (Table 6 for the details). The results of spoken data were only obtained from a subgroup of the learners (twelve learners in the lowest proficiency level group) (see Table 5).

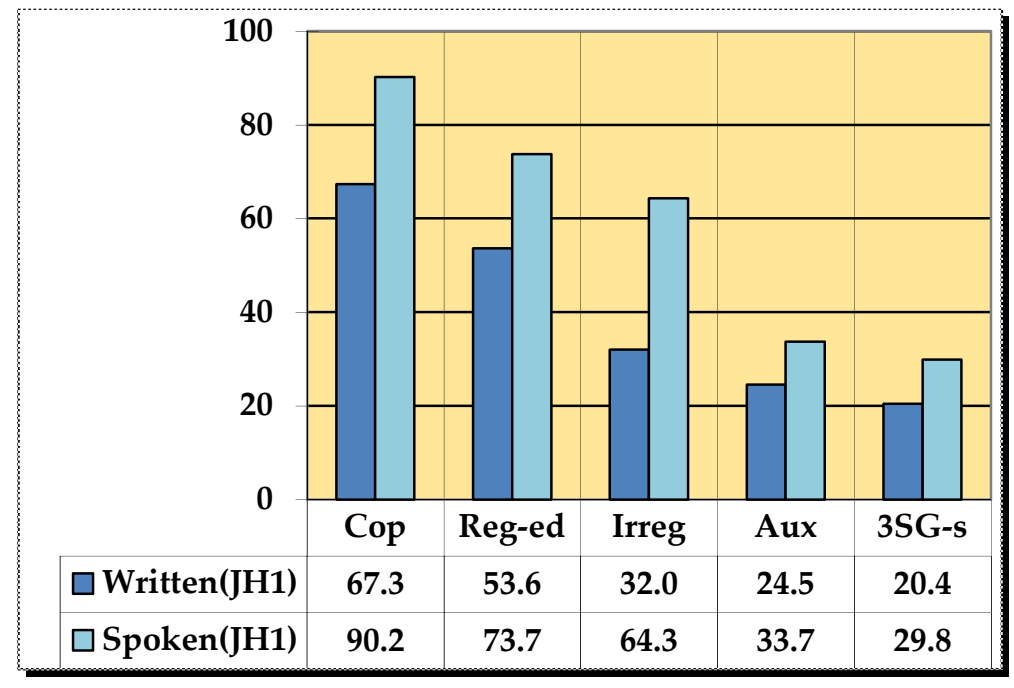

Figure 3. Accuracy rates of verbal morphology in obligatory contexts (\%).

\subsection{Error Types of Tense-Aspect Morphology}

The tense-aspect morphology showed another difference in the type of errors from other L2 English studies. With regard to past tense (-ed), the overuse (e.g., drinked) was found in irregular past contexts (Figure 4), although Hawkins and Casillas (2008, p. 610) found "little overgeneration of $-e d$ " in the results of early Chinese and Spanish learners of English. One-way ANOVA shows no significant difference $(p>0.10)$ between the two production tasks but a significant difference (written: $\mathrm{F}(2,27)=36.52, p<0.001$; spoken: $\mathrm{F}(2,9)=7.06, p<0.001)$ between the error types. The multiple comparisons by Holm method confirm a statistically significant difference the error types in both production data $(p<0.005)$ (written: omission and misuse $-s /$ omission and overuse $-e d$; spoken: omission and misuse $-s)$. 


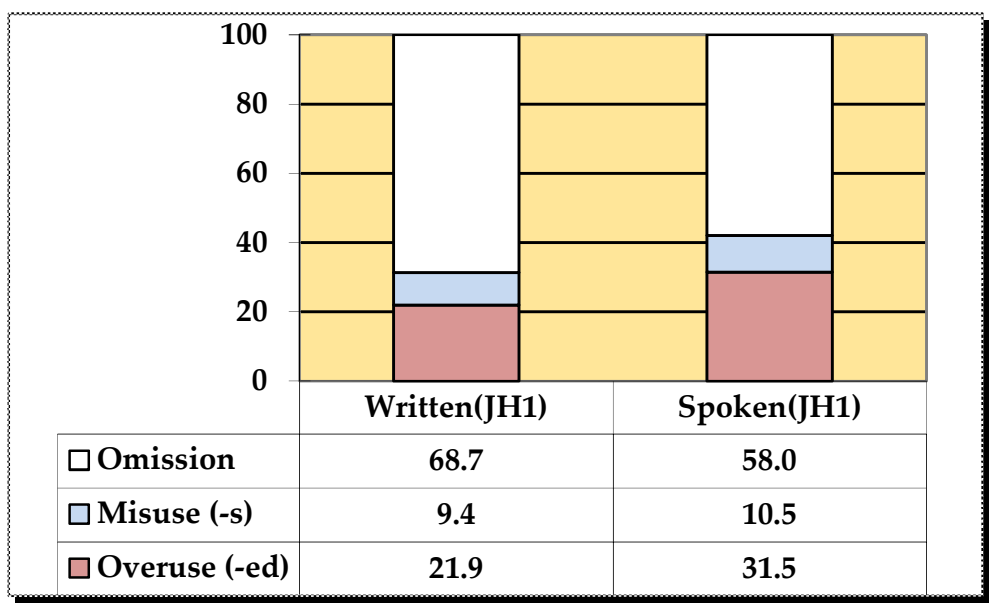

Figure 4. Overuse of regular past -ed in irregular past forms in obligatory affirmative with and without VP-adverb contexts (see Table 6) (\%).

Figure 5 demonstrates a contrast in omission between $-e d$ and $-s$. One-way ANOVA confirms a statistically significant difference between the two kinds of omission rates (written: $F(1,28)=55.90$, $p<0.001$; spoken: $\mathrm{F}(1,10)=323.40, p<0.001)$. This is similar to the results of a Yoshimura and Nakayama (2009)Yoshimura and Nakayama study which shows a significant difference between them $(p<0.0014)$. The respective accuracy rates (Figure 2$)$ inversely correspond to their omission rates.

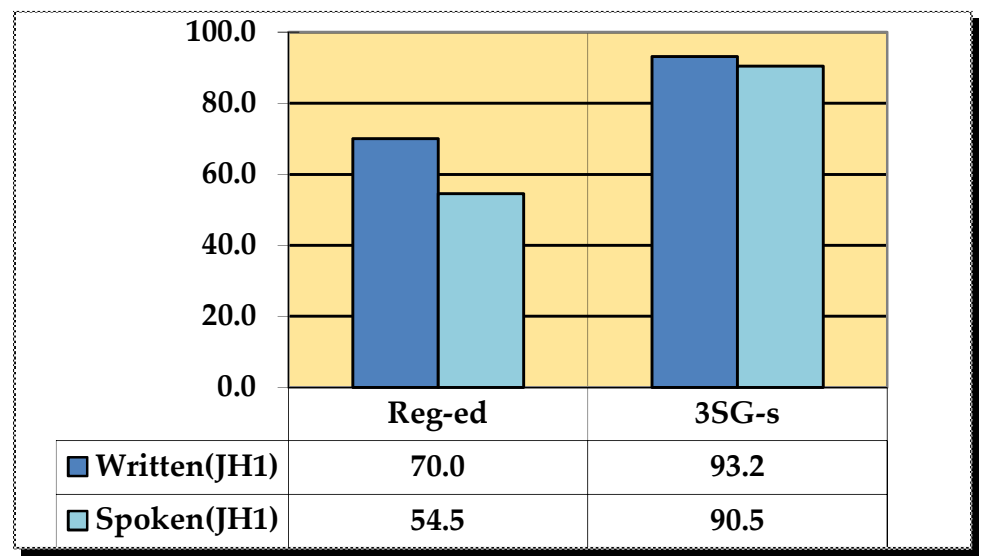

Figure 5. Omission rates of $-e d$ and $-s$ in obligatory contexts (\%).

Turning to imperfective aspect $b e+-i n g$, most of the errors were the misuse of bare verbs (e.g., He study Japanese now) and of 3SG -s (e.g., She eats breakfast now.), as shown in Figure 6. By contrast, in previous L2 English studies, few cases of misused $-s$ were observed in non 3SG $-s$ contexts. Ionin (2013, p. 517) mentions that "misuse of verbal morphology was essentially non-existent": "only 5 percent in Ionin and Wexler (2002), and 3 percent in Haznedar (2001) as well as White (2003a)". The remaining cases were -ing omission, appearing as be + bare V constructions (e.g., He is read a book now) (see Figure 6). However, neither auxiliary be omission errors (e.g., He reading) nor the misuse of perfective aspect marker have + -en were found in this study. One-way ANOVA shows no significant difference $(p>0.10)$ between the two production tasks but a significant difference between the error types (written: $\mathrm{F}(2,27)=26.45, p<0.001$; spoken: $\mathrm{F}(2,9)=24.80, p<0.001)$. The multiple comparisons by Holm method confirm a statistically significant difference between the error types (misuse and ing omission/misuse and be omission) in both production data $(p<0.005)$. 


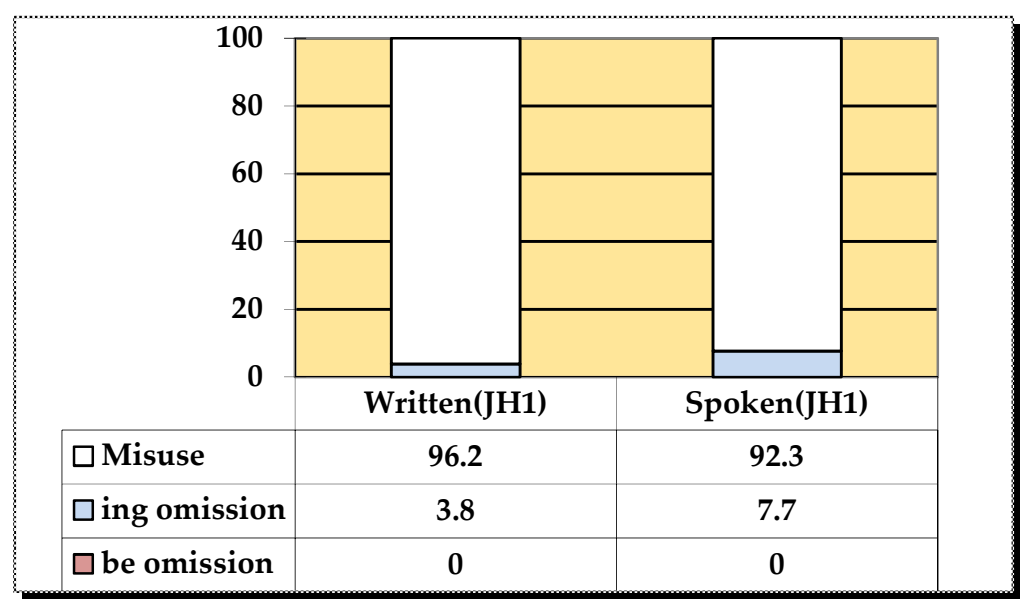

Figure 6. Misuse of bare verbs and 3SG $-s$ in auxiliary be $+-i n g(\%)$.

Furthermore, the results revealed that L1 Japanese learners across groups produced the tense and aspect morphology that clashed with adverbs and adverbial phrases, as given in Examples (18 and 19).

18. a. *She sometimes drinks milk last year.

[JH 1st, No. 11, Spoken]

(No.30 She sometimes drank milk last year.)

b. *She often plays_ piano last year.

[JH 3rd, No.1, Written]

(No.2 She often played the piano last year.)

c. *She doesn't go to school yesterday.

[JH 2nd, No.20, Written]

(No.15 She didn't go to school yesterday.)

d. *She didn't go to bed early every night.

[JH 3rd, No.12, Written]

(No.42 She doesn't go to bed early every night.)

19. a. *He studies Japanese now.

[JH 1st, No.2, Spoken]

(No. 33 He is studying Japanese now.)

b. *She eats breakfast now.

[U 2nd, No.10, Written]

(No.8 She is eating breakfast now.)

c. ${ }^{*}$ He didn't read _ book now.

d. *He doesn't read_book now.

[JH 1st, No.12, Spoken]

[JH 1st, No.2, Written]

(No.33 He isn't reading a book now.)

\section{Discussion and Conclusions}

\subsection{Discussion of Findings}

The primary goal of the current study was to investigate why L1 Japanese young instructed learners would show variability in the L2 acquisition of English verbal morphology, by testing the FRH's predictions. The feature-based hypothesis attributes L2 morphological variability to L1-L2 contrasts in the two learning tasks (feature selection and assembly), where the three determinants of L2 learnability are assumed: (1) the same feature selection; (2) the different configurations; (3) morpholexical correspondences (see Section 3). It is assumed that the different configurations of the same features which exist in both L1 and L2 could hinder the feature-reassembly process, while the morpholexical correspondences could facilitate the process.

The application of the two underlying assumptions (the two learning tasks and three determinants of L2 learnability above) to the L1 Japanese-L2 English pairing is as follows (see Section 3, Table 3). First, both past tense markers are similarly encoded by the same feature [+past] with morpholexical correspondences. Second, non-past tense markers, on the other hand, show different configurations 
of the same feature [-past] with no morpholexical similarity. Japanese has a single non-past tense marker $-(r) u$ that denotes [-past] with any phi-features, while English has two kinds of non-past tense markers. One non-past tense form - $\varnothing$ (zero suffix) denotes [-past] with [1st/2nd person] and [+/- singular], but the other non-past tense serves as an agreement marker $-s$ that encodes a specific bundle of three features [-past] [3rd person] and [+singular]. Third, imperfective aspect markers exhibit an asymmetry in feature-assembly between Japanese and English. The Japanese marker -tei-ru denotes three aspectual features ([+progressive], [+habitual], and [+resultative]), while the English discontinuous marker be + -ing encodes a single feature [+progressive]. Under the FRH, it is predicted as follows (repeated Section 5.1):

(1) L2 Japanese learners will easily be able to reassemble [+past] into an L2 item -ed.

(2) L2 Japanese learners will have more difficulty in realising an unfamiliar composition of [-past] with [3rd person] [+singular] on a single new morpholexical form $-s$.

(3) L2 Japanese learners will face even more of a challenge in reconfiguring only one feature [+ progressive] into a pair of L2 items be + -ing.

In both written and spoken production data elicited by the picture-stimulus task, L1 Japanese young instructed learners across all learner groups showed variable productions among L2 English verbal morphology, as reported in Section 6. Most importantly, the results differed as to the accuracy of tense-aspect morphology, compared to the previous L2 English studies (see Figures 1 and 2). In other words, this study revealed the accuracy order with regular past $-e d$ and auxiliary be reversed, which is incompatible with "the fact that auxiliaries and the copula are supplied to a much greater extent than inflectional morphology on lexical verbs, and with considerable accuracy" (White 2008, p. 307). Results from all learner groups appear to confirm the FRH's underlying assumptions. This suggests that their different performances of tense-aspect morphology may be correlated with the three determinants of L2 learnability and correspond to the three predictions above.

With regard to the first prediction, all participant groups exhibited relatively high accuracy of regular past-tense marker. This indicates that Japanese L2 young learners appear to succeed in reassembling [+past] into the L2 regular past-tense marker -ed. This could be attributable to both the same configuration of the same feature [+past] and one-to-one morpholexical correspondence, which would facilitate the feature-reassembly process, as in a study by Song and Schwartz (2009), where early L1 English learners of L2 Korean regard Korean mwues as the English counterpart what. The favourable conditions are assumed to trigger the overuse of $-e d$ in irregular past form contexts (see Figure 4), which is the error type hardly found in the other L2 English study (Hawkins and Casillas 2008). The high accuracy and the overused -ed might lend some support to Lardiere (2009, p. 191, 213)'s assumption that "L2 learners initially seek L1-L2 morpholexical equivalents of assembled lexical items in the L1 in the target language" "based on semantic meaning or grammatical function".

In relation to the second prediction, Japanese young learners, regardless of the length of English exposure, revealed the lowest accuracy and the highest omission of 3SG $-s$ (Figures 2 and 5). The results reflect a failure in the reassembly of [-past] with the other two features into a single item $-s$, due solely to the complicatedly different configurations of the same feature [-past] without any morpholexical correspondence. This suggests that it might be more difficult for L2 learners to both select a language-specific unfamiliar combination of multiple features and fuse them into a single morpheme. The highest omission of 3SG $-s$ (93.2\% of the written; $90.5 \%$ of the spoken, see Figure 5) could be evidence for the relative difficulty of the reconfiguration for L1 Japanese learners.

As for the final prediction, all learner groups showed the relatively low accuracy rates of auxiliary be. This might mirror particular difficulty with the reassembly of only one [+progressive] into a discontinuous imperfective aspect marker $b e+-i n g$. This suggests that the feature-reassembly process could be impeded by the unfavourable conditions: (1) asymmetric configurations including the same feature [+progressive] between L1 Japanese and L2 English; (2) zero morpholexical correspondence. Japanese learners of English thus would have to eliminate the L1 feature assembly of the other two 
aspectual features [+habitual] [+resultative] on -tei-ru. Ionin and Montrul (2010, p. 907) suggest that "selecting features for a new category is easier than reassembling features on an existing category" in a study of L2 acquisition of English by L1 Spanish/Korean advanced adult learners. This provides some support for the argument that it is easier to learn new properties in the L2 than to unlearn the existing properties in the L1 (Gabriele and Hughes 2015). The misused $-s$ or $-\varnothing$ (zero suffix $=$ bare verbs) in obligatory progressive be + -ing contexts might mirror a failure to delink another [+habitual] feature bundled in the Japanese counterpart -tei-ru. In other words, the high rate of the misuse (96.2\% written, $92.3 \%$ spoken) appears to verify the unlearning challenge for L1 Japanese learners. This suggests that L1 Japanese learners are more likely to select [+habitual] and reassemble it into the corresponding L2 lexical items $-s / \varnothing$ in obligatory progressive contexts.

However, it should be noted that misused perfective aspect have $+-e n$ was completely non-existent, although three groups of the young instructed learners (except JH first grade ${ }^{26}$ ) had already learned the discontinuous perfective form. The total absence of the misused have $+-e n$ might be associated with lexical aspect classes of verbs. Lexical aspect, unlike grammatical aspect, is encoded by the inherent properties of verbal phrases, which are classified into four classes, based on the aspectual semantic features (see Table 1 in Section 2). Specifically, this study included no achievement verbs with which both Japanese $(-t e i-r u)$ and English (have $+-e n)$ perfective aspect markers encode [+resultative]. The lexical verbs used in the question items were activity (e.g., swim, walk, laugh ${ }^{27}$ ), accomplishment (e.g., read a book, eat cake, buy a ticket, drink milk), and stative (like) verbs, all of which allow --tei-ru to denote [+habitual], as well as [+progressive]. This is the limitation of this study which will have to be overcome in future research to further investigate how the lexical aspect of verbs could affect the two continuous acquisition processes and whether the FRH's predictions are fully borne out.

As explained above (see Section 2), temporal and aspectual notions are realised, interacting with grammatical markers (tense-aspect morphology), the properties of the lexical verb phrases (lexical aspect), and other components like adverbs/adverbial phrases (Olsen 1997; Smith 1991, 1997; Verkuyl 1993). However, the overall results revealed that all learner groups tended to produce tense and aspect morphology which was inconsistent with adverbs (e.g., now, today) and adverbial phrases (e.g., last night, every day), ${ }^{28}$ as given in the examples (here a partial repetition of earlier examples from 18 and 19).

20. *She sometimes drinks milk last year.

21. a. *He studies Japanese now.

b. *She eats breakfast now.
[JH 1st, No. 11, Spoken]

[JH 1st, No.2, Spoken]

[U 2nd, No.10, Written]

It should be assumed that L1 Japanese young instructed learners rely heavily on adverbs/adverbial phrases to encode tense and aspect in L2 English. This could reflect a more crucial role of adverbs/adverbial phrases in Japanese, which would be attributable to the "aspectual ambiguity" in L1 Japanese lexical verbs (Tsujimura 2007, p. 385), particularly in achievement and stative verbs, due to the different composition of the aspectual features (see Section 2.2).

Furthermore, it should be noted that Japanese learners, regardless of their English class hours, exhibited $100 \%$ target-like overt nominative subjects, which could be evidence that they had acquired the tense category and the relevant specified features. Specifically, overt nominative subjects reflect

26 The junior high school students in this study were scheduled to learn the present perfect tense from the second term of the second grade onward.

27 Other examples from the study are: study Japanese, write letters, play tennis / baseball/the piano, cook dinner, read comic books, go to bed / a restaurant, watch $T V$.

28 Confirmation that all learners understood the adverbs used in the tasks was obtained from the relevant teaching staff. 
three syntactic operations: (1) subject-verb agreement that needs [3rd person] [+singular] features; (2) subject raising that requires [EPP]; (3) nominative case marking that needs [finite]. The results suggest that the variable production of verbal morphology could not be attributable to underlying impairment to the functional categories and features.

\subsection{Conclusions and Directions of Future Research}

L1 Japanese young instructed learners across all groups have demonstrated differences in accuracy rates and error types of tense-aspect morphology, compared to those of previous L2 English studies. Regular past tense marker $-e d$ showed a higher accuracy rate than auxiliary be did: copula be $>$ regular past $-e d>$ irregular past forms $>$ auxiliary $b e>3 S G-s$. The related error types exhibited overused $-e d$ in irregular past form contexts and misused $-s$ and bare verbs in progressive $b e+-i n g$ contexts, both of which were hardly observed in the previous L2 studies. These findings lend some support to the FRH's prediction that ascribes morphological variability to L1-L2 contrasts in feature assembly. This suggests a prominent role of L1 in morphological production, to which success in past -ed and failure in auxiliary be could be attributable. In other words, reassembly of feature matrices for morpholexical items is likely to determine the relative ease or difficulty in L2 acquisition. Future research will cover all lexical aspectual classes of verbs in test items, in order to examine whether misused have $+-e n$, like misused $-s / \varnothing$, could occur, assuming that the inherent properties of lexical verbs are involved in the acquisition processes. This could provide solid evidence for the argument that it might be difficult for L2 learners to unlearn already-assembled morpholexical items from the L1. Furthermore, in future research, it would be crucial to carry out bidirectional research. Specifically, applying the key assumptions to the opposite L1 English-L2 Japanese pairing could allow further work to validate the predictive power of the FRH. This could lead to a clearer understanding of L1 transfer in L2 acquisition of inflectional morphology.

Funding: This research received no external funding.

Acknowledgments: The original study was presented both in the 27th European Second Language Association (Reading, UK, August-September 2017) and the 50th British Association for Applied Linguistics (Leeds, UK, September 2017). I am deeply grateful to the anonymous reviewers, the audience, Tomohiko Shirahata, Koji Suda, Neal Snape, and Alexandra Vraciu for their valuable comments and suggestions. My sincerest gratitude goes to Carol Jaensch on her helpful advice. Further thanks go to Nobuhiro Hikami and Hiroyuki Takita, as well as teachers and participants, for generous cooperation in my research.

Conflicts of Interest: The author declares no conflict of interest.

\section{References}

Andersen, Roger W., and Yasuhiro Shirai. 1994. Discourse motivations for some cognitive acquisition principles. Studies in Second Language Acquisition 16: 133-56. [CrossRef]

Chomsky, Noam. 2000. Minimalist Inquiries: The Framework. In Stey by Step: Essays in Minimalist Syntax in Honor of Howard Lasnik. Edited by Roger Martin, David Michaels and Juan Uriagereka. Cambridge: MIT Press, pp. 89-155.

Chomsky, Noam. 2001. Derivation by phrase. In Ken Hale: A Life in Language. Edited by Michael Kenstowicz. Cambridge: MIT Press, pp. 1-52.

Chomsky, Noam. 2005. Three factors in language design. Linguistic Inquiry 36: 1-22. [CrossRef]

Comrie, Bernard. 1976. Aspect. Cambridge: Cambridge University Press.

Dekeyser, Robert M. 2005. What makes learning second-language grammar difficult? A review of issues. Language Learning 55: 1-25. [CrossRef]

Diaz, Lourdes, Aurora Bel, and Konstantina Bekiou. 2008. Interpretable and Uninterpretable Features in the Acquisition of Spanish Past Tenses. In the Role of Formal Features in Second Language Acquisition. Edited by Juana M. Liceras, Helmut Zobl and Helen Goodluck. London: Routledge, pp. 484-512.

Fujii, Tadashi. 1996. Doushi + te iru no imi [The Meaning of verb + te iru]. Kokugo Kenkyuu Shitsu 5. In Nihongo doshi no asupekuto [The Aspect of Japanese Verbs]. Edited by Haruhiko Kindaichi. Tokyo: Mugi Shobo, pp. 97-116. 
Gabriele, Alison, and Mamori Sugita Hughes. 2015. Handbook of Japanese Psycholinguistics. In Tense and Aspect in Japanese as a Second Language. Edited by Mineharu Nakayama. Boston: De Gruyter Mouton, pp. 271-302.

Gabriele, Alison. 2008. Calculating Telicity in Native and Non-Native English. In Proceedings of the 9th Generative Approaches to Second Language Acquisition Conference (GASLA 2007). Edited by Roumyana Slabakova, Jason Rothman, Paula Kempchinsky and Elena Gavruseva. Somerville: Cascadilla Proceedings Project, pp. 37-46.

Geçkin, Vasfiye, and Belma Haznedar. 2008. The morphology/syntax interface in child L2 acquisition: Evidence from verbal morphology. In Current Trends in Child Second Language Acquisition: Generative Perspective. Edited by Belma Haznedar and Elena Gavruseva. Amsterdam: John Benjamins, pp. 237-267.

Goad, Heather, Lydia White, and Jeffry Steele. 2003. Missing inflection in L2 acquisition: Defective syntax or L1-constrained prosodic representation? Canadian Journal of Linguistics 48: 243-63. [CrossRef]

Grüter, Theres, and Simone Conradie. 2006. Investigating the L2 initial state: Additional evidence from the production and comprehension of Afrikaans-speaking learners of German. In Inquiries in Linguistic Development: In Honor of Lydia White. Edited by Roumyana Slabakova, Silvina Montrul and Philippe Prévost. Amsterdam: John Benjamins, pp. 89-114.

Halle, Morris, and Alec Marantz. 1993. Distributed Morphology and the Pieces of Inflection. In The View from Building 20: Essays in Linguistics in Honor of Sylvain Bromberger. Edited by Kenneth Locke Hale and Samuel Jay Keyser. Cambridge: MIT Press, pp. 111-76.

Hawkins, Roger, and Gabriela Casillas. 2008. Explaining frequency of verb morphology in early L2 speech. Lingua 118: 595-612. [CrossRef]

Hawkins, Roger, and Hajime Hattori. 2006. Interpretation of English multiple wh-questions by Japanese speakers: A missing uninterpretable feature account. Second Language Research 22: 269-301. [CrossRef]

Haznedar, Belma. 2001. The acquisition of the IP system in child L2 English. Studies in Second Language Acquisition 23: 1-39. [CrossRef]

Hopp, Holger. 2010. Ultimate attainment in L2 inflection: Performance similarities between non-native and native speakers. Lingua 120: 901-31. [CrossRef]

Ionin, Tania, and Kenneth Wexler. 2002. Why is 'is' easier than '- $\mathrm{s}^{\prime}$ ?: Acquisition of tense/agreement morphology by child second language learners of English. Second Language Research 18: 95-136. [CrossRef]

Ionin, Tania, and Silvina Montrul. 2010. The role of transfer in the interpretation of articles with definite pluralsin L2 English. Language Learning 60: 877-925. [CrossRef]

Ionin, Tania. 2013. Morphosyntax. In The Cambridge Handbook of Second Language Acquisition. Edited by Julia Herschensohn and Martha Young-Scholten. Cambridge: Cambridge University Press, pp. 505-28.

Iwasaki, Shoichi. 2013. Japanese. Amsterdam: John Benjamin.

Kibort, Anna, and Greville G. Corbett. 2010. Features: Perspectives on a Key Notion in Linguistics. Oxford: Oxford University Press.

Lardiere, Donna. 2008. Feature assembly in second language acquisition. In The Role of Formal Features in Second Language Acquisition. Edited by Juana M. Liceras, Helmut Zobl and Helen Goodluck. New York: Routledge, pp. 106-40.

Lardiere, Donna. 2009. Some thoughts on the contrastive analysis of features in second language acquisition. Second Language Research 25: 173-227. [CrossRef]

Li, Yen-Hui Audrey. 1999. Plurality in a classifier language. Journal of East Asian Linguistics 8: 75-99. [CrossRef]

Ogihara, Toshiyuki. 1999. Tense and Aspect. In The Handbook of Japanese Linguistics. Edited by Natsuko Tsujimura. Malden: Blackwell Publishing, pp. 326-48.

Olsen, Mari Broman. 1997. A Semantic and Pragmatic Model of Lexical and Grammatical Aspect. New York: Garland Publishing.

Radford, Andrew. 2009. Analysing English Sentences. Cambridge: Cambridge University Press.

Robinson, Richard R. 1995. The Aspect Hypothesis revisited: A cross-sectional study of tense and aspect marking in interlanguage. Applied Linguistics 16: 344-70. [CrossRef]

Rothstein, Susan. 2004. Structuring Events: A Study in the Semantics of Lexical Aspect. Oxford: Blackwell.

Shirai, Yasuhiro. 2002. The Aspect Hypothesis in SLA and the acquisition of Japanese. Acquisition of Japanese as a Second Language 5: 42-61.

Slabakova, Roumyana. 2008. Meaning in the Second Language (Studies in Language Acquisition Series 34). New York: De Gruyter Mouton. 
Slabakova, Roumyana. 2016. Second Language Acquisition. Oxford: Oxford University Press.

Smith, Carlota. 1991. The Parameter of Aspec. Dordrecht: Kluwer.

Smith, Carlota. 1997. The Parameter of Aspect, 2nd ed. Kluwer: Dordrecht.

Song, Hyang Suk, and Bonnie D. Schwartz. 2009. Testing the Fundamental Difference Hypothesis: L2 Adult, L2 Child, and L1 Child Comparisons in the Acquisition of Korean "Wh"-Constructions with Negative Polarity Items. Studies in Second Language Acquisition 31: 323-61. [CrossRef]

Sugaya, Natsue, and Yasuhiro Shirai. 2007. The acquisition of progressive and resultative meanings of the imperfective aspect marker by L2 learners of Japanese. Studies in Second Language Acquisition 29: 1-38. [CrossRef]

Sugita, Mamori. 2009. Japanese -te iru and -te aru: The Aspectual Implications of the Stage-Level and Individual-Level Distinction. Graduation Dissertation. New York: City University of New York.

Tsimpli, Ianthi Maria, and Maria Mastropavlou. 2008. Feature interpretability in L2 acquisition and SLI: Greek clitics and determiners. In The Role of Formal Features in Second Language Acquisition. Edited by Juana-M. Liceras, Helmut Zobl and Helen Goodluck. London: Routledge, pp. 142-83.

Tsujimura, Natsuko. 2007. An Introduction to Japanese Linguistics, 2nd ed. Blackwell Publishing: Malden.

Vendler, Zeno. 1967. Linguistics and Philosophy. Ithaca: Cornell University Press.

Verkuyl, Henk J. 1993. A Theory of Aspectuality: The Interaction between Temporal and Atemporal Structure. Cambridge: Cambridge University Press.

White, Lydia. 2003a. Fossilization in steady state L2 grammars: Persistent problems with inflectional morphology. Bilingualism: Language and Cognition 6: 129-41. [CrossRef]

White, Lydia. 2003b. Second Language Acquisition and Universal Grammar. Cambridge: Cambridge University Press.

White, Lydia. 2008. Some puzzling features of L2 features. In The Role of Formal Features in Second Language Acquisition. Edited by Juana M. Liceras, Helmut Zobl and Helen Goodluck. London: Routledge, pp. 300-26.

Yoshimura, Noriko, and Mineharu Nakayama. 2009. Nominative case marking and verb inflection in L2 grammar: evidence from Japanese college students' compositions. In The Proceedings of the 2009 Tokyo Conference on Psycholinguistics. Tokyo: Hitsuji Shobo, pp. 359-83.

Yuan, Boping. 2010. Domain-wide or variable-dependent vulnerability of the semantics-syntax interface in L2 acquisition? Evidence from wh-words used as existential polarity words in L2 Chinese grammars. Second Language Research 26: 219-60. [CrossRef]

(C) 2018 by the author. Licensee MDPI, Basel, Switzerland. This article is an open access article distributed under the terms and conditions of the Creative Commons Attribution (CC BY) license (http:// creativecommons.org/licenses/by/4.0/). 